\title{
Academic integrity, STEM education, and COVID-19: a call to action
}

\author{
Kristal Louise Turner ${ }^{1}$ (D) . Jennifer D. Adams ${ }^{2}$ (D) $\cdot$ Sarah Elaine Eaton $^{1}$ (D)
}

Received: 4 January 2021 / Accepted: 22 October 2021 / Published online: 26 February 2022

(c) The Author(s), under exclusive licence to Springer Nature B.V. 2022

\begin{abstract}
With the global pandemic educators have had to move their courses to virtual spaces, and this quick change has brought up concerns, especially in STEM education where there are ongoing discussions of adapting laboratories and shifting lecture and assessment practices to online learning. One issue that has become more pressing, beyond the financial and technological implications, is that of academic integrity violations. This position paper looks at the intersection academic integrity and equity and social justice in STEM higher education, where there is a lack of research and publications exploring the inequities that exist. The researchers have expertise in these areas and hold positions in as faculty, student, and advisor. The paper's main focus represents a review of the current literature and calls educators to action to change the narratives in STEM and higher education, taking into account the impact of COVID-19 and the shift in the education conversations that have happened due to the pandemic.
\end{abstract}

Keywords EDJ $\cdot$ STEM $\cdot$ Academic integrity

With the global pandemic educators have had to move their courses to virtual spaces, and with little notice or course preparation. This quick change has brought up concerns, especially in STEM education where there are ongoing discussions of adapting labs and shifting lecture and assessment practices to online learning. However, one issue that has become more pressing is that of academic integrity violations. Academic integrity is defined as "a commitment, even in the face of adversity, to six fundamental values: honesty, trust, fairness, respect, responsibility, and courage" (International Center for Academic Integrity,

Lead editor: C. Siry

Kristal Louise Turner

kllumsde@ucalgary.ca

Jennifer D. Adams

jennifer.adams1@ucalgary.ca

Sarah Elaine Eaton

seaton@ucalgary.ca

1 Werklund School of Education, University of Calgary, Calgary, Canada

2 Facutly of Chemistry, Werklund School of Education, University of Calgary, Calgary, Canada 
n.d.; para 1). Within the STEM fields, integrity and ethics are discussed in the context of standards and practices within the disciplines, however beyond these practices, the common discourse of academic integrity is not around what it constitutes, but rather the ways it is violated, thus the discussions center around cheating and plagiarism (Gilmore, Maher, and Feldon 2016.) Although universities have policies to manage breaches of academic integrity, the rhetoric points to punitive measures and individual responsibility without a deeper exploration of the underlying structures that contribute to these issues (Stoesz, Eaton, Miron, and Thacker 2020). Furthermore, there is a lack of literature and considerations of equity and social justice (ESJ) in academic integrity. This includes the ways that students from racialized and other minoritized groups, first generation students, students for whom English is not their first language and students with disabilities experience academic integrity. With the shift to online learning, this also includes students who are in environments that are not conducive to effective online learning. For example, not having adequate internet access, having limited use or shared technology, or not having dedicated spaces for learning. These issues should be of concern in STEM education where there already exists large inequities in students who pursue STEM and an embedded culture of "weeding out" students, especially in the entry-level course, which leaves them unable to access advanced STEM studies that can lead to prestigious STEM careers (Chawla 2020; Wolff 2019).

STEM majors and fields have long standing issues of inequity. Students who are Black, Indigenous and Latinx and with other intersecting identities, such as gender and firstgeneration status remain underrepresented in STEM (National Academies of Sciences, Engineering, and Medicine 2016). Existing literature describes the systemic barriers that include lack of effective mentors (Ashford, Wilson, King, and Nyachae 2017; Walkington 2017), experiences of biases and microaggressions (Caxaj, Chau, and Parkins 2018; McPherson 2017), whiteness and patriarchal culture of science (Le and Matias 2019; Cedillo 2018; Wynter 2003) and lack of institutional support structures to foster retention and success (Ong, Wright, Espinosa, and Orfield 2011). Because we have not yet examined how racialized and minoritized students experience academic integrity, it may very well present another barrier that contributes to the long-standing inequities in STEM.

COVID-19 has allowed educators to shift the conversation around STEM and academic integrity in many ways. As academics in North America who are concerned with social justice, we witnessed the existing inequities in STEM education and education more broadly become intensified with the ongoing pandemic. The migration of course assessments online has heightened concerns about student academic misconduct and students cheating on examinations. Furthermore, with campuses closing, issues of student access to adequate technology and internet connections became an increasing concern. We also understand that many of us, both faculty and students alike, have been in survival mode during the COVID-19 crisis. A rapid review conducted by Eaton and Turner (2020) revealed that students' anxiety levels have been heightened with managing course loads with the move to emergency remote learning. However, when issues are amplified, it provides the opportunity to carefully examine the underlying complexities to inform research agendas and policy reform with equity in mind. With our individual expertise in equity, STEM and academic integrity, we recognized that literature that connected these areas was lacking and potentially detrimental to achieving equity in STEM and postsecondary education. In this article we will discuss the intersections of STEM education, equity and social justice (EDJ), and academic integrity as a space that warrants interrogation in the context of equity. First, we explore what academic integrity issues look like in STEM. We then describe how the underlying neoliberalism that produces inequities in STEM education 
that also contributes to student academic misconduct. Then concluding the article with a call to action for educators.

\section{Academic integrity and STEM}

Emphasizing the role of the individual in the context of STEM and STEM education, the neoliberal ideology that structures education also influences how we view academic integrity. In the past, academic integrity has been viewed as a moralistic issue, one more about the character of a person and less about the conditions that lead to academic misconduct (Adam 2016; Eaton and Turner 2020). Bazzul (2012) notes that neoliberalism is a global ideology that forms the foundation of how many institutions operate. A key tenet of neoliberalism is meritocracy which is a social system based on individual education and wealth attainment (Strong, Adams, Bellino, Pieroni, Stoops, and Das 2016). This system has become the standard in STEM and values grades and competition over engaged learning and creative problem solving. Traditional assessment practices are damaging to STEM education and reflect neoliberal underpinnings of education today, "by misapplying standardized and efficiency-driven practices favored by businesses to education, neoliberal reforms have constrained the social imaginary of science education within the limits and contradictions of capitalism" (Strong, Adams, Bellino, Pieroni, Stoops, and Das 2016, p. 225). The emphasis on testing to determine knowledge creates stress in students to succeed (Wolff 2019). In a discussion around the reasons why STEM students "plagiarize or cheat," Gilmore, Maher and Feldon (2016) proposed reasons that include poor time management, unmeaningful assignments and ready availability of information on the Internet. They also noted that some students may not view cheating as in conflict with their personal values, for example students from collectivist cultures are more likely to believe that knowledge is owned by society.

Therefore, existing literature about academic integrity is often from the position of 'how do STEM students cheat?' rather than 'why do STEM students cheat?' More than a decade ago, Bertram Gallant (2008) argued that we should move away from questions about cheating altogether, an instead focus on why students are (or are not) learning. She further suggested that we avoid viewing academic integrity through the lens of moral binaries and instead asserted that academic integrity is a teaching and learning imperative. Emphasizing the role of the individual in the context of STEM education, grades are viewed by both faculty and students as the main barrier for engaging in more meaningful learning, creative practices and risk-taking in STEM (Paton, Adams, and Turner 2021). Assessments of learning are often reduced to grades or traditional knowledge assessment standards, like examinations and portfolios. These standards create hierarchies where those who do well on these traditional assessments are positioned as intelligent and capable STEM students, whereas those who do not achieve the grades may be forced out of the STEM stream (Wolff 2019). With STEM courses being viewed as a gateway to prestigious and potentially lucrative careers, the compulsion to engage in misconduct is greater, because the repercussions of failure are higher (Wade-Jaimes 2020).

Science courses, especially the entry level courses are meritocracies within schooling. Grades are a "cost-effective" way to rank those who are "successful" and weed out those who do not fit that traditional mold. This deeply embedded system is considered neutral and fair, reflecting the presumed objectivity of science. A system based on individual ability and the presumed idea that everyone has equal opportunity at success. This neglects to consider the 
inequitable structures that different individuals experience in their science schooling, such as access to inadequate laboratories and technologies, upper-level science classes in their precollege education; with COVID-19 these structures have become more pronounced. Science education thus becomes enclosed or "privately owned" by people who have existing economic and racial advantages. Because of the high stakes involved in STEM education, some students are compelled to achieve the grades they need for education and economic advancement by any means necessary (Wolff 2019).

\section{Inequity in STEM}

The biases that present in STEM education are often in relation to perceptions about students' abilities and/or their belonging in STEM spaces. For example, one study of an informal STEM pathways program found that racialized and minoritized students felt isolated, undervalued and disregarded by their peers and faculty in postsecondary STEM even though they built strong STEM identities in the pre-college program (Habig, Gupta, Levine and Adams 2020). Furthermore, faculty can also be consciously or unconsciously complicit in their beliefs about STEM ability and race, along with academic integrity issues, and this often leads to students feeling disrespected, targeted, or unmotivated (Canning, Muenks, Green, and Murphy 2019). There is increasing evidence of overreporting of academic integrity among particular student populations, including students of color (Eaton 2021). These perceptions can undoubtedly influence issues of academic integrity. It is possible that students who experience devaluing and exclusion, who are viewed as not belonging in STEM spaces would be more likely to get singled out for academic misconduct.

The move to online learning has amplified inequity in STEM. Research has demonstrated that COIVD-19 unequally impacts minoritized and otherwise marginalized people in several ways. First, the infection rates have been higher in Black, Indigenous, Latinx and lower income communities (Poteat, Millett, Nelson, and Beyrer 2020; CDC 2020). People from these same communities also form most of the essential worker populations which left those communities greater exposed to the virus. The shelter-in-place mandates and corresponding online learning left many economically disadvantaged students with inadequate technology and limited dedicated space for studying. Netzahuatl (2020) pointed out that first-generation, lower-income students are opting to stay on campus, even with the courses all being online, because it was more conducive to studying. The move to online learning, assessments became a compounded challenge for EDJ in STEM, with some universities using proctoring services to allegedly "prevent cheating," which impact racialized students negatively. Proctoring technology uses facial recognition algorithms to detect cheating behaviors and those algorithms cannot detect darker skin tones, further propagating inequities for students of color (Parnther 2020). This technology has also proven to be heteronormative, sexist, and unable to process movement disorders, thus maintaining the status quo of white, male, (neuro)typical, as the standard and successful norm for a student (Eaton and Turner 2020; Swauger 2020). As well, online testing platforms and learning management systems provide options that prevent students from backtracking on online quizzes and examinations, which can be detrimental for students with reading or concentration disabilities (Raje and Stitzel 2020). These systems are punitive and punish students for who they are, rather than assessing what they know. 


\section{Working the intersection of EDI, academic integrity and STEM education}

As mentioned, the literature that integrates EDJ, STEM education and academic integrity is scant. This presents the opportunity to lay the foundation for research and corresponding practice and policy that centers questions about student learning; what promotes engagement and positive learning experiences in their field, rather than supports to prevent student cheating (Ridgeway 2019). This compels us to ask what are the different ways that students can demonstrate learning in STEM courses and focus on less procedural experiences.

It is important first to identify the inequities or bias that exist in STEM and how they affect the norms and practices in science education. STEM programs tend to see more academic misconduct issues because students are taught to trust more in numeric data and have less experience with referencing and citations in papers, which can lead to ethical or misconduct issues (Andrews, Smith, Henzi, and Demps 2007; Duff, Zamecnik, Pardo, and Smith 2020; Gilmore et al. 2016). The structures of bias need to be problematized, as they often seem settled on continuing the white status quo and harming the futures of those who are marginalized (Delpit 2006). For example, we know from previous research in postsecondary STEM education that Black, Indigenous, Latinx, and students with disabilities experience systemic barriers to participation in STEM, we also need to see if these patterns extend to academic integrity as this would present another hurdle for these-and othergroups of students to navigate. We need to be clear about where inequities currently exist at an institution - and within educational systems broadly - and what steps are needed to improve things for all stakeholders. While we are addressing the systemic barriers, that are more complex and time intensive, the immediate shift could be to frame discussions of academic integrity around what students need in order to be more successful in their STEM program. This approach is more empathetic, respectful, and takes academic integrity infringements beyond punishments (Boisvert, Teymouri, Medicine Crane, and Eaton 2020; Eaton 2020a, 2020b).

\section{Structuring STEM education to support student learning and engagement}

STEM education spaces should be designed to support student learning and sense belonging. Passive, non-inclusive science education practices place the burden of learning on the individual learner rather than in the collaborative practices of a community (Labouta, Adams, and Cramb 2018). This is heightened by COVID-19 and the isolation that comes for some students participating in virtual classrooms. Whether virtual or in-person it is important to consider inclusive course design that emphasizes authentic assessments, which can include group or portfolio projects of the student's choice, reflection as selfassessment, peer grading, group discussions, and interweave in topics of academic integrity as relevant to the discipline (Raje and Stitzel 2020). This would allow students to engage more holistically in practices of the STEM field, be less procedural, more critical, and learn about academic integrity in a more embedded and relevant way. Being less procedural and more creative in their learning would allow for more qualitative practices in 
STEM and begin to open the field beyond the role of quantitative or numerical learning. In virtual learning environments, planning synchronous and asynchronous activities could help students with time and task management, including having scheduled help sessions for students who may be struggling with content and/or the learning format.

Although the practice of doing scientific research is collaborative, this is often not reflected in grading practices of current STEM classes. This is a disconnect between academic norms, which are more individual, and scientific practices that tend to be done in laboratories or teams, that needs to be integrated to give students a more authentic experience and support their ability to think in novel ways. Students and educators may experience confusion in how to demonstrate their independent learning and accounting and how to use ideas and work from their collaborating peers when demonstrating knowledge (Gilmore, Mahler, and Feldon 2016). However, collaborative work presents the opportunity to both engage in authentic scientific practices and discussing issues of integrity in collaborative work. This collaborative work could be as simple as role-playing a scenario that impacts humans, like climate change scenarios or adding in diverse ways of viewing science learning. Sharing with students authoring, attributing and citation practices in the field is also a way of apprenticing students into the practices of the field.

Pedagogical approaches that center the affective needs of learners could help to foster spaces of equity and belonging. For example, deep teaching, as an inclusive pedagogical model, emphasizes relationality through the centering empathy and instructor self-awareness, "a pedagogy predicated on relationships requires an understanding of self before one can fully engage students," (Dewsberry 2020, p. 175). This self-awareness includes recognizing implicit biases as well as the "historical and social contexts that inform the students' presence in the classroom (p.178). This means recognizing both the cultural and social attributes that students bring to the classroom and the challenges that could keep them from being fully engaged. For example, a student who is learning at home while managing childcare has different needs than a student who is learning from home but in student residence. This is an important need not only during a global pandemic but in moving forward to equitable and just STEM participation (Fig. 1).

\section{Call to action}

We conclude with a call to action for empathetic teaching, learning and policy approaches that focus on student learning and support. We contend that there is a greater need to value learning as a lifelong process of cognitive, social and ethical development. Such an approach empowers students to be more focused on becoming the best future science professionals that they become rather than viewing science courses as a hurdle to overcome in relation to their career endeavors. Further we emphasize the need for more empirical research to understand academic integrity through the lens of equity that centers students' identities as learners and a sense of belonging and flourishing in STEM pursuits. Academic integrity is not about avoiding misconduct, or adhering to a set of regulations, but rather about practicing ethical decisions daily in learning institutions to habituate the process. Learning this daily practice of ethical decision-making positions our students for success not only in school, but long after they have graduated, as well. 


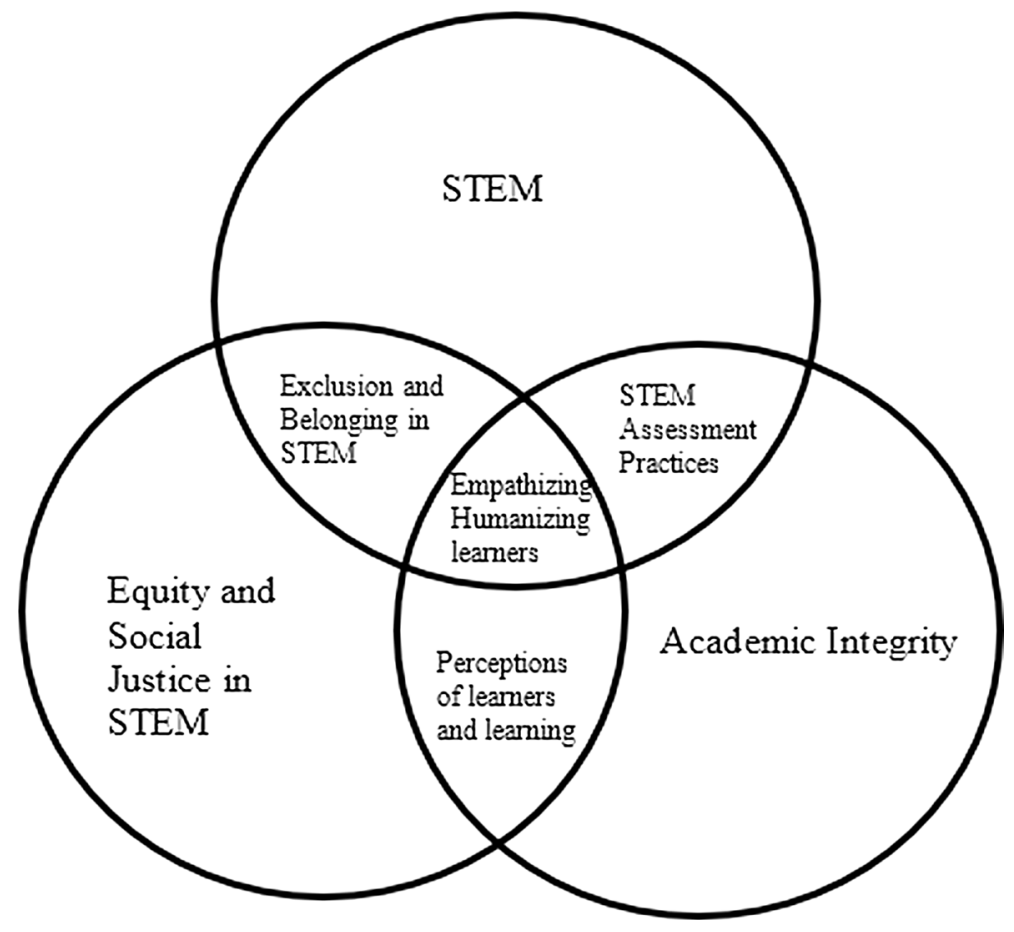

Fig. 1 Illustrates the intersections of STEM Education, Equity and Social Justice (ESJ) and academic integrity (AI) and key words describing existing literature. STEM Education and ESJ literature describe barriers that contribute to exclusion and strategies for belonging. ESJ and AI literature emphasizes student (personal) responsibility, experiences and perceptions of students who are called out for academic integrity violations, and ways to prevent issues of AI. STEM and AI literature points to STEM exclusive engagement and assessment practices, such as high stakes courses and examinations. Where the three meet, we propose examining systemic/institutional issues that contribute to the dehumanization of learners and countering this by centering empathy

\section{Declarations}

Conflict of interest We have no conflict of interests to disclose.

\section{References}

Adam, L. (2016). Student perspectives on plagiarism. In T. Bretag (Ed.), Handbook of academic integrity (pp. 519-535). London: Springer.

Andrews, K. G., Smith, L. A., Henzi, D., \& Demps, E. (2007). Faculty and student perceptions of academic integrity at U.S. and Canadian dental schools. Journal of Dental Education, 71(8), 1027-1039. https:// doi.org/10.1002/j.0022-0337.2007.71.8.tb04369.x

Ashford, S. N., Wilson, J. A., King, N. S., \& Nyachae, T. M. (2017). STEM SISTA spaces. Emerging Issues and Trends in Education, 2017, 3.

Bazzul, J. (2012). Neoliberal ideology, global capitalism, and science education: Engaging the question of subjectivity. Cultural Studies of Science Education, 7(4), 1001-1020.

Bertram Gallant, T. (2008). Academic integrity in the twenty-first century: A teaching and learning imperative. Wiley. 
Boisvert, S., Teymouri, N., Medicine Crane, J. A., \& Eaton, S. E. (2020). Exploring racism and academic integrity through a circle process. Paper presented at the Alberta Teachers' of English as a Second Language (ATESL) annual conference, Online. http://hdl.handle.net/1880/112689

Canning, E.A., Muenks, K., Green, D.J. \& Murphy, M.C. (2019). STEM faculty who believe ability is fixed have larger racial achievement gaps and inspire less student motivation in their classes.

Caxaj, C. S., Chau, S., \& Parkins, I. (2018). How racialized students navigate campus life in a mid-sized Canadian city: 'thrown against a white background 'but 'comfortable enough to laugh.' Race Ethnicity and Education, 24, 1-20.

Cedillo, S. (2018). Beyond inquiry: Towards the specificity of anti-blackness studies in STEM education. Canadian Journal of Science, Mathematics and Technology Education, 18(3), 242-256.

Centers for Disease Control and Prevention. (2020). COVID-19 in racial and ethnic minority groups. https:// www.cdc.gov/coronavirus/2019-ncov/need-extra-precautions/racial-ethnic-minorities.html

Chawla, DS. (2020, November 16). Surviving weed-out classes in science may be a state of mind. The New York Times. https://www.nytimes.com/2020/11/16/science/weed-out-classes-stem.html

Delborne, J. A. (2016). Suppression and dissent in science. In T. Bretag (Ed.), Handbook of Academic Integrity. Singapore: Springer. https://doi.org/10.1007/978-981-287-098-8_30

Delpit, L. (2006). The silenced dialogue: Power and pedagogy in educating other people's children. In Other people's children: Cultural conflict in the classroom, (pp. 21-47). The New Press. https://doi.org/10. 17763/haer58.3.c43481778r528qw4

Dewsbury, B. M. (2020). Deep teaching in a college STEM classroom. Cultural Studies of Science Education, 15(1), 169-191.

Duff, A., Zamecnik, A., Pardo, A., \& Smith, E. (2020, March 23-27). The SEIRA approach: Course embedded activities to promote academic integrity and literacies in first year engineering. In Proceedings of the 10th international conference on learning analytics and knowledge. Learning and Analytics \& Knowledge Conference. https://lak20.solaresearch.org/list-of-accepted-papers

Eaton, S. E. (2020b). Race-based data in student conduct: A call to action. University of Calgary. http://hdl. handle.net/1880/112157

Eaton, S. E. (2020a). Academic integrity: Combating systemic racism. Retrieved from http://hdl.handle.net/ $1880 / 112156$

Eaton, S. E. (2021). Plagiarism in higher education: Tackling tough topics in academic integrity. Libraries Unlimited.

Eaton, S. E., \& Burns, A. (2018). Exploring the intersection between culturally responsive pedagogy and academic integrity among EAL students in Canadian higher education. Journal of Educational Thought, 51(3), 339-359.

Eaton, S. E., \& Turner, K. L. (2020). Exploring academic integrity and mental health during COVID-19: Rapid review. Journal of Contemporary Education Theory \& Research, 4(1), 35-41.

Gilmore, J., Mahler, M., \& Feldon, D. (2016). Prevalence, prevention, and pedagogical techniques: Academic integrity and ethical professional practice among STEM students. In T. Bretag (Ed.), Handbook of Academic Integrity (pp. 10.1007/978-981-287-079-7_45-1). Springer.

Habig, B., Gupta, P., Levine, B., \& Adams, J. (2020). An informal science education program's impact on STEM major and STEM career outcomes. Research in Science Education, 50(3), 1051-1074.

Hofstra, B., Kulkarni, V. V., Galvez, S. M. N., He, B., Jurafsky, D., \& McFarland, D. A. (2020). The diversity-innovation paradox in science. Proceedings of the National Academy of Sciences, 117(17), 9284-9291.

International Center for Academic Integrity. (n.d). Fundamental values of academic integrity. https://www. academicintegrity.org/fundamental-values/

James, C. E., \& Turner, T. (2017). Towards race equity in education: The schooling of black students in the Greater Toronto Area. York University.

Labouta, H. I., Adams, J. D., \& Cramb, D. T. (2018). An integrative cultural model to better situate marginalized science students in postsecondary science education. Cultural Studies of Science Education, 13(3), 785-796.

Le, P. T., \& Matias, C. E. (2019). Towards a truer multicultural science education: How whiteness impacts science education. Cultural Studies of Science Education, 14(1), 15-31.

McPherson, E. (2017). Oh you are smart: Young, gifted African American women in STEM majors. Journal of Women and Minorities in Science and Engineering, 23(1).

Natcher, D., Bogdan, A. M., Lieverse, A., \& Spiers, K. (2020). Gender and Arctic climate change science in Canada. Palgrave Communications, 6(1), 1-8.

National Academies of Sciences, Engineering, and Medicine. (2016). Barriers and opportunities for 2-Year and 4-Year STEM degrees: Systemic change to support diverse student pathways. In S. Malcom \& M. Feder (Eds.), Board on science education, division of behavioral and social sciences and education. 
Board on higher education and the workforce, policy and global Affairs. The National Academies Press. https://doi.org/10.17226/21739

Netzahuatl, B. (2020). The new Columbia bubble: First generation, low income students form the majority in pandemic-era dorms. The Eye. https://www.columbiaspectator.com/the-eye/2020/12/14/new-colum bia-bubble-first-generation-low-income-students-form-the-majority-in-pandemic-era-dorms/

Ong, M., Wright, C., Espinosa, L., \& Orfield, G. (2011). Inside the double bind: A synthesis of empirical research on undergraduate and graduate women of color in science, technology, engineering, and mathematics. Harvard Educational Review, 81(2), 172-209.

Parnther, C. (2020, October 9). Creating a culture of equity in academic integrity: Best practices for teaching and learning. webinar presented at the taylor insitute of teaching and learning. University of Calgary. https://youtu.be/59mBo9neEgY

Paton, C., Adams, J., \& Turner, K. (2021, April 7-10). Students' understandings and experiences of creativity and risk in science learning [paper presentation]. NARST, Orlando, Florida.

Poteat, T., Millett, G., Nelson, L. E., \& Beyrer, C. (2020). Understanding COVID-19 risks and vulnerabilities among black communities in America: The Lethal Force of syndemics. Annals of Epidemiology., $47,1-3$.

Raje, S., \& Stitzel, S. (2020). Strategies for effective assessments while ensuring academic integrity in general chemistry courses during COVID-19. Journal of Chemical Education, 97(9), 3436-3440.

Ridgeway, M. (2019). Against the grain: Science education researchers and social justice agendas. Cultural Studies of Science Education, 14, 283-292. https://doi.org/10.1007/s11422-019-09939-6

Stoesz, B. M., Eaton, S. E., Miron, J. B., \& Thacker, E. (2019). Academic integrity and contract cheating policy analysis of colleges in Ontario, Canada. International Journal for Educational Integrity, 15(4), 1-18. https://doi.org/10.1007/s40979-019-0042-4

Strong, L., Adams, J. D., Bellino, M. E., Pieroni, P., Stoops, J., \& Das, A. (2016). Against neoliberal enclosure: Using a critical transdisciplinary approach in science teaching and learning. Mind, Culture, and Activity, 23(3), 225-236. https://doi.org/10.1080/10749039.2016.1202982

Swauger, S. (2020, August 7). Software that monitors students during tests perpetuates inequality and violates their privacy. MIT Technology Review. https://www.technologyreview.com/2020/08/07/10061 32/software-algorithms-proctoring-online-tests-ai-ethics/

Wade-Jaimes, K. (2020). 'STEM girls should be': A discourse analysis of school structures and their impact on African American, middle school girls' positioning in science. Discourse: Studies in the Cultural Politics of Education. https://doi.org/10.1080/01596306.2020.1742094

Walkington, L. (2017). How far have we really come? Black women faculty and graduate students' experiences in higher education. Humboldt Journal of Social Relations, 39, 51-65.

Wolff, R.D. (2019, August 5). Grades are capitalism in action. Let's get them out of our schools. Truthout. https://truthout.org/articles/grades-are-capitalism-in-action-lets-get-them-out-of-our-schools/?fbclid= IwAR21ICPICG1GBj0F6Xz9uQsWKEkkSaQTMqbs_AaKfdLrBChVhVx8kwy3urc

Wynter, S. (2003). Unsettling the coloniality of being/power/truth/freedom: Towards the human, after man, its overrepresentation-An argument. CR The New Centennial Review, 3(3), 257-337. https://doi.org/ 10.1353/ncr.2004.0015

Publisher's Note Springer Nature remains neutral with regard to jurisdictional claims in published maps and institutional affiliations.

Kristal Louise Turner is a MA student at the University of Calgary, Werklund School of Education.

Jennifer D. Adams is an Associate Professor and Tier II Canada Research Chair in the Department of Chemistry and the Werklund School of Education.

Sarah Elaine Eaton is an Associate Professor and Chair, Leadership, Policy, and Governance Specialization, Werklund School of Education and Educational Leader in Residence, Academic Integrity,Taylor Institute for Teaching and Learning. 